\title{
Efficacy and safety of pulsed radiofrequency modulation of thoracic dorsal root ganglion or intercostal nerve on postherpetic neuralgia in aged patients: a retrospective study
}

Xuehua Huang ${ }^{1 \dagger}$, Yanfeng Ma ${ }^{2 \dagger}$, Weimin Wang ${ }^{3 \dagger}$, Yunxiu Guo ${ }^{4 \dagger}, \mathrm{Bo} \mathrm{Xu}^{5^{*}}$ and Ke Ma ${ }^{{ }^{*}}$

\begin{abstract}
Background: Postherpetic neuralgia (PHN) is common in elderly patients and can be alleviated by pulsed radiofrequency (PRF). However, PRF treatments display different efficacy on different nerves. The purpose of this study was to evaluate the efficacy and safety of ultrasound-guided PRF modulation on thoracic dorsal root ganglion (DRG) or intercostal nerve (ICN) for PHN in aged patients and to provide a theoretical basis for clinical treatment.
\end{abstract}

Methods: We classified aged patients into two groups, DRG group and ICN group, based on the needle tip position. Visual analogue scale (VAS) and concise health status questionnaire (Short-form 36 health/survey questionnaire, SF-36) were used to evaluate the pain intensity and the life quality of the patients before and 2, 4 and 12 weeks after the PRF treatments. We also recorded the adverse reactions during the treatments.

Results: After the PRF treatment, the scores of VAS and SF-36 (assessing general health perception, social function, emotional role, mental health, and pain) improved significantly in both groups $(P<0.05)$. The mean VAS score in the DRG group was significantly lower than that in the ICN group 2 weeks after treatment, and remained for 12 weeks. The SF-36 scores in the DRG group were significantly higher than those in the ICN group $(P<0.05)$. We found a similar incidence of adverse reactions between the two groups $(P>0.05)$.

Conclusions: PRF therapy is safe and effective for elderly patients with postherpetic neuralgia. However, PRF treatment in dorsal root ganglion is superior to that in intercostal nerve with improving VAS and SF-36 scores to a greater extent in older patients.

Trial registration: ChiCTR2100044176.

Keywords: Pulsed radiofrequencies, Postherpetic neuralgia, Dorsal root ganglion, Intercostal nerve, The aged patients

\footnotetext{
*Correspondence: xubo@xinhuamed.com.cn; make@xinhuamed.com.cn

${ }^{\dagger}$ Xuehua Huang, Yanfeng Ma, Weiming Wang and Yunxiu Guo contributed

equally to this work.

${ }^{1}$ Department of Pain, Xinhua Hospital, Shanghai Jiaotong University

School of Medicine, Shanghai, PR China

${ }^{5}$ Department of Anesthesiology and Surgical Intensive Care Unit, Xinhua

Hospital, Shanghai Jiaotong University School of Medicine, Shanghai, PR

China

Full list of author information is available at the end of the article
}

(C) The Author(s) 2021. Open Access This article is licensed under a Creative Commons Attribution 4.0 International License, which permits use, sharing, adaptation, distribution and reproduction in any medium or format, as long as you give appropriate credit to the original author(s) and the source, provide a link to the Creative Commons licence, and indicate if changes were made. The images or other third party material in this article are included in the article's Creative Commons licence, unless indicated otherwise in a credit line to the material. If material is not included in the article's Creative Commons licence and your intended use is not permitted by statutory regulation or exceeds the permitted use, you will need to obtain permission directly from the copyright holder. To view a copy of this licence, visit http://creativecommons.org/licenses/by/4.0/. The Creative Commons Public Domain Dedication waiver (http://creativeco mmons.org/publicdomain/zero/1.0/) applies to the data made available in this article, unless otherwise stated in a credit line to the data. 


\section{Introduction}

Postherpetic neuralgia (PHN) is a chronic pain caused by varicella-zoster virus infection, which always occurs among older adults. People suffer from PHN over 50 years old accounts for $12.5 \%$ patients with PHN [1]. And PHN prevalence increases with advancing age $[1,2]$.

The typical clinical symptoms of $\mathrm{PHN}$ is a persistent sharp or burning pain with spontaneous pain [3], which seriously affects the elderly patients' quality of life. Its pathogenesis is complicated making it difficult to be treated [4]. A variety of treatments is applied into the clinical practice, which include drug therapy and minimally invasive therapeutic procedures (nerve blocks, pulsed radiofrequency, neurolysis, and so on). Drug treatments are unlikely to fundamentally solve the patients' clinical symptoms, and some patients have to cease the medications due to their side effects, especially the elderly [5].

Pulsed radiofrequency (PRF) is a minimally invasive technique that applies pulsed current $(300-500 \mathrm{kHz})$ to the target nerve. The current is delivered in a pulse of $20 \mathrm{~ms}$ (45 V'voltage) followed by a silent period of $480 \mathrm{~ms}$ to avoid heat lesions [6]. Recent studies have confirmed the beneficial effects of PRF against post-operative pain, peripheral neuropathic pain, and postherpetic neuralgia [7-10]. The thoracic nerves (T1-12) are the most commonly affected by PHN with an incidence of up to $50 \%$ cases [5]. Studies have shown that both DRG and ICN with PRF treatments are effective in the treatment of thoracic postherpetic neuralgia [8]. However, no studies have compared the analgesic effects of these two methods in aged patients. The purpose of this study was to compare the clinical efficacies and security of these two PRF therapy methods for elderly patients with PHN.

\section{Methods}

\section{Patients}

The Ethics Review Committee of the Xinhua Hospital affiliated to the Medical College of Shanghai (Jiaotong University) approved this retrospective analysis (XHEC-D-2020-166). The need for a written consent from patients was waived because we ensured all the information and treatment records of the aged patients were kept anonymous to all researchers involved. The United Nations has agreed that $65+$ years may be usually denoted as old age in developed country and $60+$ as old age in developing country [11]. As a developing country, we selected $60+$ patients as the object of the study. We collected clinical data from the hospital database and analyzed the records of all PHN patients older than 60 years who received thoracic PRF treatment in the pain department between June 2017 and June 2020.
The inclusion criteria were the following: (1) pain duration > 1 month; (2) thoracic herpes zoster infection; (3) age $>60$ years; and (4) VAS score $>4$ after conservative treatment (including oral medication).

The exclusion criteria were: (1) history of cancer; (2) systemic immune disease; (3) incomplete 3 -month follow-up data; (4) receiving epidural catheter therapy or spinal cord electrical stimulation within 3 months after the PRF treatments; (4) receiving two or more times of PRF treatments.

\section{PRF procedure}

The patients were putted in the prone position on the operating table with a comfortable pillow under their chest. The PFR was carried out under large-scale Digital Subtraction Angiography (DSA, PHILIPS Company, SN:60536M151838, Holland) and B-scan ultrasound (Sonosite Company, Sonosite Edge, America) imaging. We used a PM-230 pain management generator (Baylis Medical Company, Montreal, Canada) and a 21-gauge, straight, sharp PRF cannula needle with a 5-mm exposed tip.

For the DRG treatment group: The puncture needle entered into the thoracic paraspinal space under the guidance of B-scan ultrasound (Huasheng portable ultrasound instrument, Shenzhen, China). We further adjusted the needle tip based on the DSA scanning images. Once needle tip right below the lateral edge of the vertebral pedicle in the anteroposterior view (Fig. 1A) and on the upper quadrant of the dorsal side of the intervertebral foramen in the lateral view (Fig. 1B), the position of the needle tip was controlled by sensory and motor nerve stimulation before further operation.

For the ICN group, the puncture needle entered into the low edge of the angulus costae of the corresponding intercostal nerve (Fig. 1C). After confirming the position using sensory and motor nerve electrical stimulation, the patients received PRF treatment for 3 cycles. The working mode of PRF was: $15-20$ ms pulse electric current, $45 \mathrm{~V}$ ' voltage at $42{ }^{\circ} \mathrm{C}$ for $120 \mathrm{~s}$. Impedance was maintained at less than $500 \Omega$ throughout the procedure. The vital signs of the patients (blood pressure, respiration, pulse, body temperature, and consciousness) were closely monitored during and after operation.

\section{Data collection}

We collected and analyzed the demographic data including age, gender, presence of comorbidities (such as hypertension and diabetes mellitus), and the duration and degree of pain. We also recorded and compared the VAS, SF-36 scores and side effects at 2, 4 and 12 weeks 

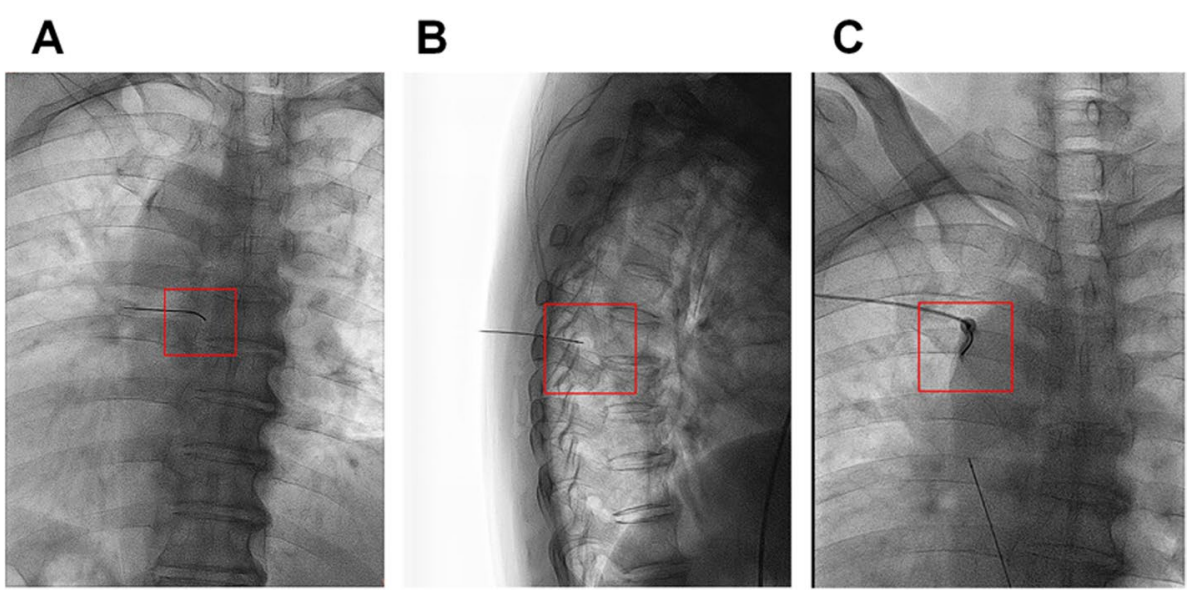

Fig. 1 X-ray photo of PRF treatment. A X-ray imaging of PRF treatment on DRG in the anteroposterior view. $\mathbf{B}$ X-ray imaging of PRF treatment on DRG in the lateral view. CX-ray imaging of PRF treatment on ICN in the anteroposterior view. PRF, pulsed radiofrequency. DRG, dorsal root ganglion. $\mathrm{ICN}$, intercostal nerve radiofrequency

after treatment between the two groups. SF-36 scores were used for evaluating the life quality, higher scores indicated better quality of life [12], including general health perception, social function, emotional role, mental health index, pain index, physical function, physical role, and vitality. We also recorded data on adverse reactions of the treatments.

\section{Statistical analysis}

SPSS 26.0 software was used to analyze all the data in this study. Continuous variables with normal distribution were expressed as Mean $\pm \mathrm{SD}$, while non-normally distributed data were expressed as median \pm interquartile range. We chose repeated measurement variance analysis to compare continuous measurement of data between the two groups. Chi-square tests were used to compare composition ratios of two different groups. $P$-values $<0.050$ is regarded as statistically significant.

\section{Results}

In this retrospective study, we collected the data of 205 aged patients who underwent PRF. Among the 108 patients who underwent DRG PRF treatments, 12 patients were excluded due to 9 patients with malignant tumors, 2 patients with systemic immune disease, and 1 patient with two times of PRF treatments. At last, we included 96 patients. For the 97 aged patients who underwent ICN PRF, 7 patients had malignant tumors, 3 patients had desmosis, and 4 patients had two times of PRF treatments. In the end, we analyzed data from 83 patients (Fig. 2).

Table 1 described the demographic characteristics of the aged patients in the study. We found no significant differences in age, gender, pain duration, or other medical history features between the patients in the DRG and ICN groups $(P>0.05)$. The differences in VAS and SF-36 scores between the two groups before treatments were not statistically significant $(P>0.05)$.

After treatments for 2 weeks, VAS scores in the DRG group were significantly lower than those in the ICN group, and the score gap increased at 4 weeks and remained so until 12 weeks after treatments $(P<0.01$; Fig. 3$)$.

We compared SF-36 scores between two groups at 2, 4 and 12 weeks after treatments and found that pain index in the DRG treatment group was significantly lower than that in the ICN treatment group at 2 weeks after treatments and remained so until the 12 weeks post-treatment $(P<0.01)$. The levels of general health perception, social function, emotional role, and mental health index in the DRG treatment group were generally better than those in the ICN treatment group $(P<0.05)$. The scores for physical function, physical role, and vitality were similar in both groups after treatment $(P>0.05$; Fig. 4$)$.

During the operation, one patient (1\%) developed a pneumothorax in the ICN group. And one patient (1\%) was found with the needle penetration of the subarachnoid space in the DRG group. The patient with pneumothorax completely recovered with oxygen therapy for 2 days. The patient where the needle penetrated the subarachnoid space was kept supine for $6 \mathrm{~h}$ and had no further discomfort. Considering that we used B-scan ultrasound and DSA during the whole operation, the needle tip position was carefully controlled, and complications are very rare and mild. No other adverse reactions occurred, such as spinal cord injury, hematoma, limb dyskinesia and so on. 


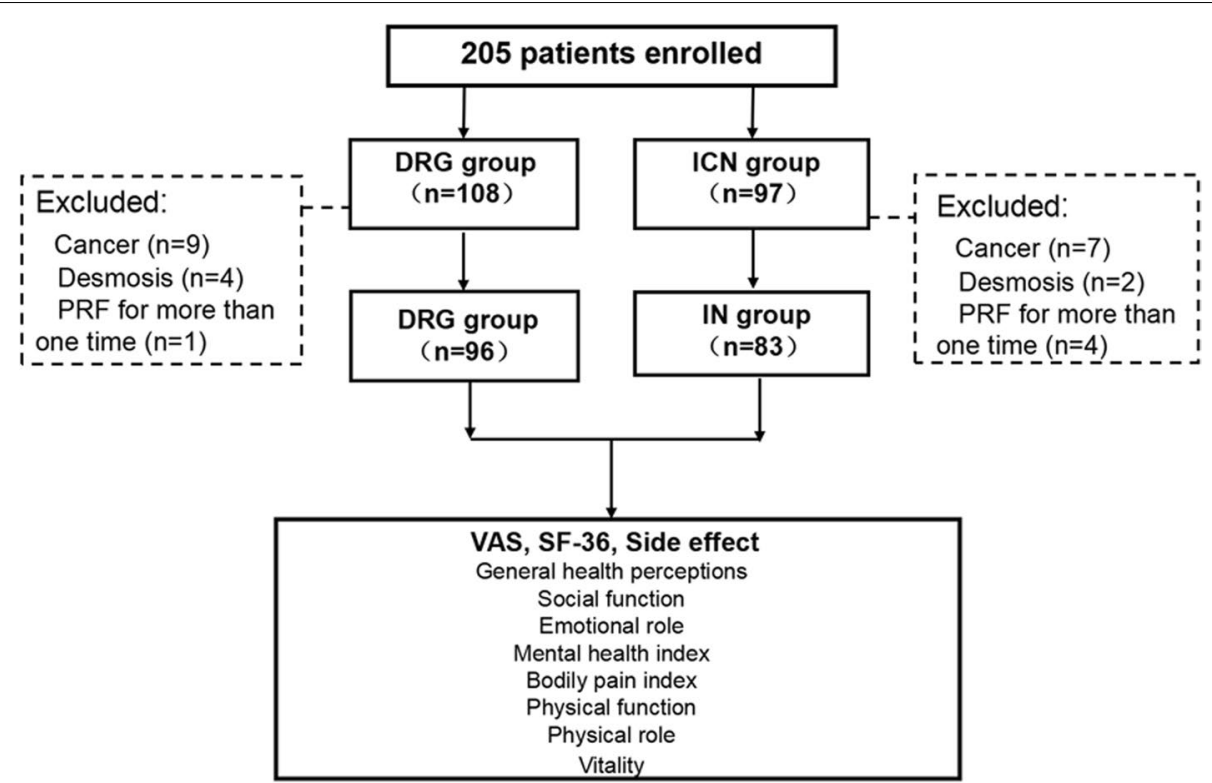

Fig. 2 Flow diagram of study patient inclusion. PRF, pulsed radiofrequency. DRG, dorsal root ganglion. ICN, intercostal nerve

\section{Discussion}

Our study results indicate that PRF treatments on different targets have different effects on PHN in aged patents. In PHN, PRF treatments at DRG seems to be superior to that at ICN, as seen by the significant VAS and SF-36 score gap between the two groups.

Table 1 Clinical characteristics of the study participants

\begin{tabular}{|c|c|c|c|}
\hline Characteristic & $\begin{array}{l}\text { DRG PRF } \\
\text { group } \\
(n=96)\end{array}$ & IN PRF group $(n=83)$ & $P$ \\
\hline Age, mean (SD), year & $70.0(7.5)$ & $70.7(7.3)$ & 0.373 \\
\hline Sex ratio (F:M) & $48: 48$ & $45: 38$ & 1.000 \\
\hline \multicolumn{4}{|c|}{ Coexisting conditions, no } \\
\hline Hypertension & 21 & 26 & 0.207 \\
\hline Diabetes & 16 & 13 & 0.983 \\
\hline $\begin{array}{l}\text { Pain duration (months), } \\
\text { (median, interquartile } \\
\text { range) }\end{array}$ & $2(1-5)$ & $2(1-5.75)$ & 0.283 \\
\hline VAS (mean, SD) & $6.0(1.26)$ & $6.02(1.29)$ & 0.454 \\
\hline \multicolumn{4}{|l|}{ SF-36 (mean, SD) } \\
\hline $\begin{array}{l}\text { General health percep- } \\
\text { tion }\end{array}$ & $43.06(6.52)$ & $43.45(6.62)$ & 0.692 \\
\hline Social function & $41.20(6.34)$ & $41.34(6.49)$ & 0.884 \\
\hline Emotional role & $44.92(6.43)$ & $45.11(6.48)$ & 0.844 \\
\hline Mental health index & $41.35(5.44)$ & $41.01(5.61)$ & 0.682 \\
\hline Bodily pain index & $35.02(6.62)$ & $35.43(6.44)$ & 0.676 \\
\hline Physical function & $54.41(6.27)$ & $54.16(6.33)$ & 0.791 \\
\hline Physical role & $55.01(6.07)$ & $54.94(6.30)$ & 0.940 \\
\hline Vitality & $41.61(6.64)$ & $41.94(6.43)$ & 0.737 \\
\hline
\end{tabular}

PHN is a kind of pain that persists 1 month after an acute herpes zoster event, and the pain in some patients may last more than 10 years $[1,2]$. Varicella-zoster virus, which causes herpes zoster, persists in the spinal nerve DRG of patients for a long time after infecting the human body. Latent viruses duplicate quickly when the body's immunity becomes lower with age [1]. Therefore, older people are more likely to develop herpes zoster and its complications PHN. Clinical studies have found that the incidence of $\mathrm{PHN}$ is as high as 60 to $75 \%$ [2] in patients over 60 years and that it seriously impacts their physical and mental health and their quality of life [13, 14]. Hence, the study focused on old patients with PHN to choose the better therapy method to improve their quality of life. The DRG suffers the most damage during PHN [15]. Firstly, the reactivated varicella-zoster virus in the DRG proliferates and destroys axons, causing demyelination and ion channel dysfunction. The damaged sensory nerves can generate abnormal electrical impulses that are transmitted to the spinal cord transmitting pain and pain hypersensitivity $[16,17]$. There are lots of inflammatory cells invading into DRG of patients with PHN [18]. Then, the inflammatory mediators transmit pain information and causes central sensitization.

The mechanisms of PRF on pain relief are complicated. Previous studies have indicated that the analgesic effect of PRF is due to the pulsed current and the biological effects. It has been demonstrated that PRF applied to the rat cervical DRG increased c-Fos immunoreactivity in the laminae of the spinal dorsal horn [19], which indicated nerve fibers have been activated by high electric 


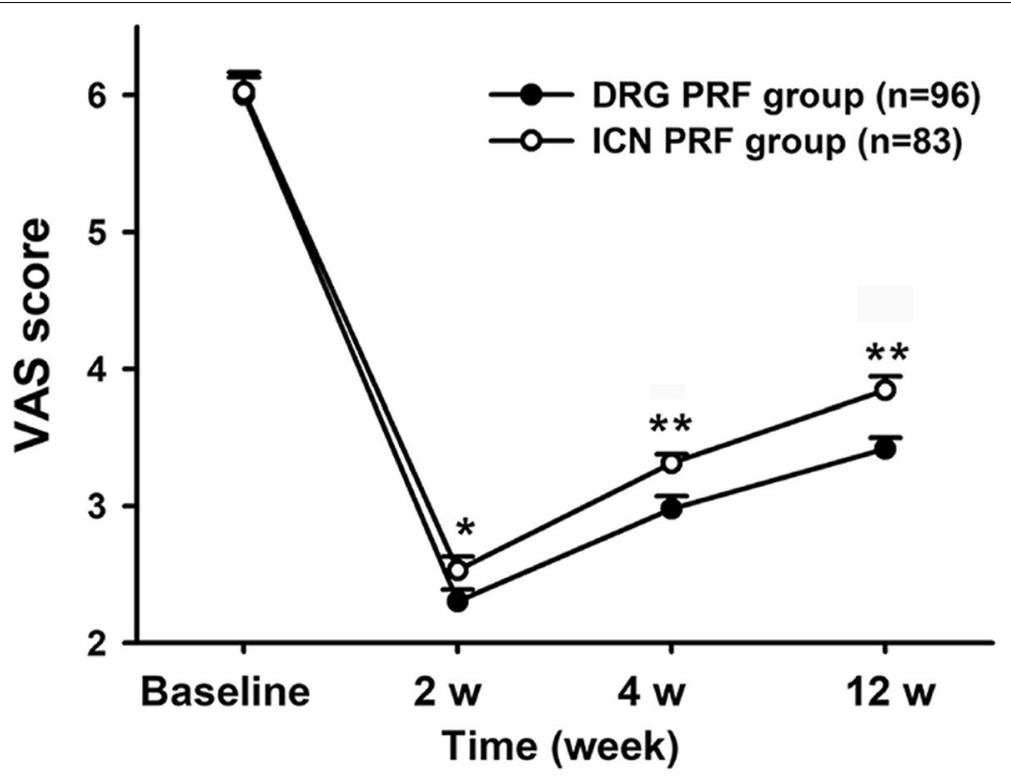

Fig. 3 The changes in VAS of the two groups. VAS, visual analogue scale DRG group, dorsal root ganglion pulsed radiofrequency group, ICN group, Intercostal nerves radiofrequency group. ${ }^{*} P<0.050$ compared to DRG group, ${ }^{* *} P<0.010$ compared to DRG group. PRF, pulsed radiofrequency. DRG, dorsal root ganglion. ICN, intercostal nerve. VAS, Visual Analogue Scale

fields. Hamann et al., also has comfirmed the biological effects of PRF, which could upregulated of ATF-3 (activating transcription factor-3, a marker of cellular stress) in the DRG neuronal bodies after applied to the L4 DRG compared to sham-operated DRG [20]. Recent studies have demonstrated that PRF could enhance the descending noradrenergic and serotonergic inhibitory pathways [21], which are involved in the modulation of neuropathic pain. From the available evidence, PRF appears to be temperature independent to regulate biological effects of cell morphology, synaptic transmission, and pain signaling.

Based on these effects, PRF has been widely applied for the treatment of PHN. Ding et al. [22] have indicated that PRF of the thoracic DRG under CT guidance is safe and effective for various PHN treatments. Ma et al. [23] have verified that PRF through the angulus costae to intercostal nerves is an effective approach for thoracic PHN and that it can last for approximately half a year. Similar with previous study, this study also confirms that PRF at DRG or ICN is effective against thoracic PHN. Different with previous study, we mainly focus on the older patients who are more susceptible to PHN and suffer longer pain than younger persons. The aged also have important pharmacokinetic and pharmacodynamic changes [24]. Renal function always decreases with aging, and drugs metabolized by the kidney should be adjusted dosage in these patients with renal impairment [25]. The aged patients always have an increased sensitivity to drugs acting on the CNS, with a result of increasing central side effects of some drugs [26]. Hence, the old patients always tolerate the medication less well than young patients. Secondly, we compare the efficacy of PRF at DRG or ICN to thoracic PRF and find PRF at DRG with better analgesic effect and higher life quality in the aged patients. In addition, both B-scan ultrasound and DSA are used during the operation, the location could be more accurate and the complications could be less.

Indeed, PRF at ICN can also relieve PHN. When the body's immunity reduces, the latent virus always replicates along the sensory nerve reaching the corresponding skin area, which results in peripheral nerve necrosis, inflammation, and demyelination [27]. Peripheral nerve sensitization plays a particularly important role in neuropathic pain. PRF reversibly blocks the transmission of nerve impulses in small or unmyelinated nerve fibers in peripheral nerve $[28,29]$. Animal studies have shown that PRF causes obvious changes in the axons of $C$ fibers by inducing mitochondria edema, abnormal ATP metabolism, changes of ion channel [30-32]. As a result, PRF at ICN decreases VAS and SF-36 scores in the old patients of our study. PRF was reported to have no damage to the axonal adventitia [33]. It is safe to use PRF of peripheral nerve to treat PHN. However, in our study, PRF of DRG is better than that of ICN.

The results of this study show that the scores of VAS and SF-36 in the DRG group were better than those in the ICN group. DRG neurons have the primary 

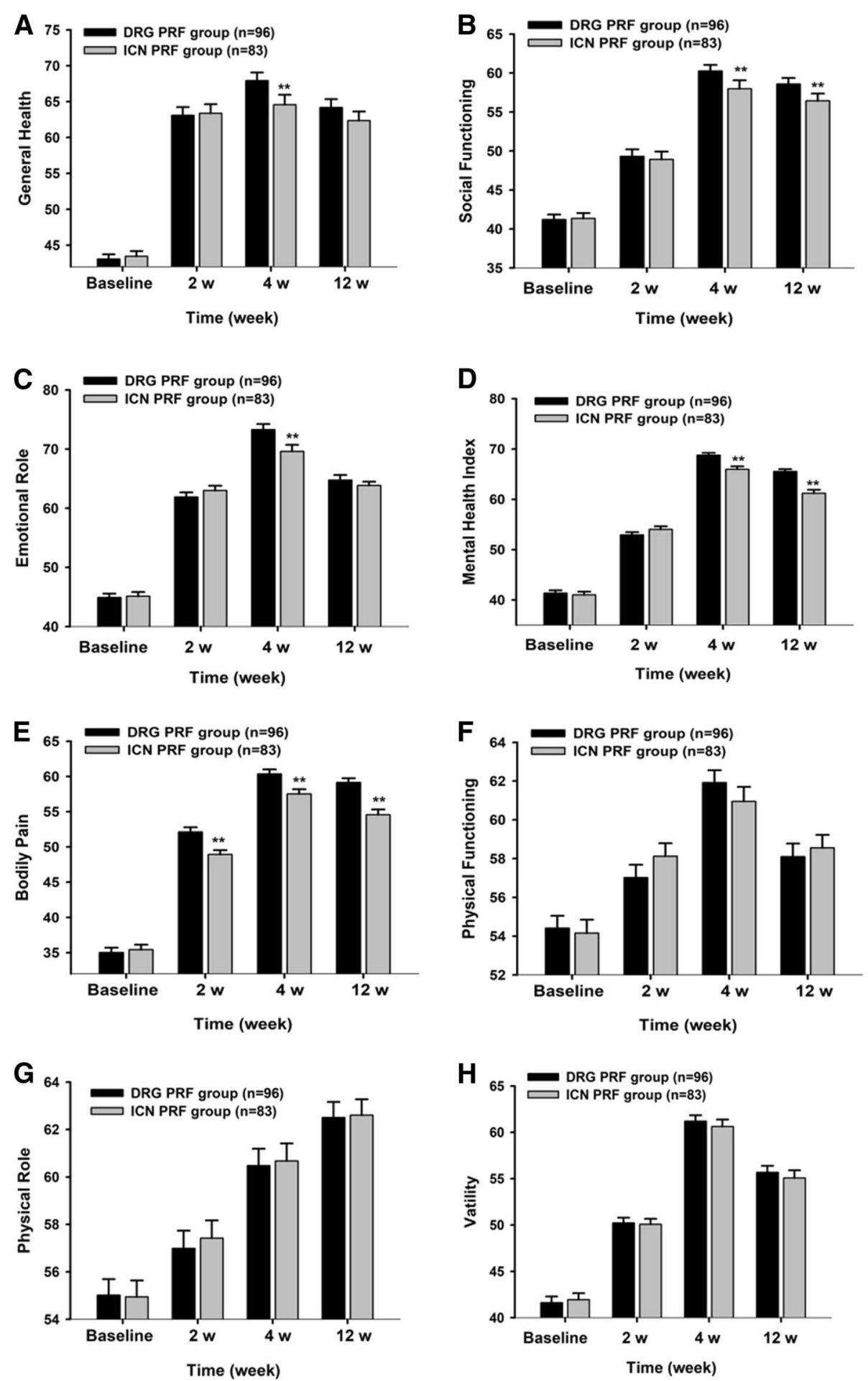

Fig. 4 The changes in SF-36 of the two groups. DRG group, dorsal root ganglion pulsed radiofrequency group. ICN group, intercostal nerve pulsed radiofrequency group group. ${ }^{* *} P<0.010$ compared to DRG group. SF-36, Short-form 36 health/survey questionnaire 
receptors of pain and temperature perceptions [5, 18]. The electrical signals of pain in the trunk are first integrated at DRGs and then transmitted to the spinal cord, which finally arrive in the central nervous system [17]. PRF can stimulate DRGs by intermittent pulse currents and block the pain signal transduction [22]. In addition, PRF could form a high voltage field around DRGs, which further inhibits the activation of glial cells [34]. However, the mechanism that PRF of DRG is better than that of ICN to treat PHN still needs further researches. Besides, as a retrospective study, it is difficult to avoid selectivity bias. Prospective studies are still needed to confirm the results of our research.

In this retrospective study, both B-scan ultrasound and DSA are used during the whole operation, complications are very rare in both groups. However, it's worth noting that a patient developed pneumothorax with lung tissue compressed less than 30\% [35]. After oxygen therapy (40\% oxygen concentration) for 2 days, the patient was found that pneumothorax was absorbed by X-ray scan. Another patient, where the needle penetrated the subarachnoid space, was left supine for $6 \mathrm{~h}$ and monitored his vital signs for 2 days. He did not have any discomfort although some patients will develop headache due to cerebrospinal fluid leakage.

In summary, the analgesic effects of PRF treatments on postherpetic neuralgia are relative to their target positions. PRF treatments in dorsal root ganglion is superior to that in intercostal nerve with improving VAS and SF-36 scores to a greater extent in older patients.

\section{Conclusion}

PRF treatment in dorsal root ganglion is recommended for older patients with postherpetic neuralgia in thoracic segment.

\section{Abbreviations \\ PHN: Postherpetic neuralgia; DRG: Dorsal root ganglion; ICN: Intercostal nerve; VAS: Visual analogue scale; SF-36: Concise health status questionnaire.}

\section{Authors' contributions}

BX and KM conceived and designed the clinical study; YG drafted this manuscript; $X \mathrm{H}$ and YM performed the clinical study; WW analyzed the data; All authors approved the final manuscript.

\section{Funding}

No funding.

Availability of data and materials

Data are available from the corresponding author on reasonable request.

\section{Declarations}

Ethics approval and consent to participate

All procedures performed in studies involving human participants were in accordance with the ethical standards of the Ethics Committee of Shanghai Jiaotong University School of Medicine (XHEC-D-2020-166) and with the 1964 Helsinki declaration and its later amendments or comparable ethical standards.

\section{Competing interests}

The authors declare that they have no conflict of interest.

\section{Author details}

'Department of Pain, Xinhua Hospital, Shanghai Jiaotong University School of Medicine, Shanghai, PR China. 'Department of Pain, The Seventh People's Hospital, Shanghai University of Traditional Chinese Medicine, Shanghai, PR China. ${ }^{3}$ Department of Pain, The Fourth People's Hospital, Yancheng, Jiangsu, PR China. ${ }^{4}$ Department of Anesthesiology, Xinhua Hospital Chongming Branch, Shanghai, PR China. ${ }^{5}$ Department of Anesthesiology and Surgical Intensive Care Unit, Xinhua Hospital, Shanghai Jiaotong University School of Medicine, Shanghai, PR China.

Received: 16 February 2021 Accepted: 10 June 2021

Published online: 24 June 2021

\section{References}

1. Vuka I, Marciuš T, Došenović S, et al. Efficacy and safety of pulsed radiofrequency as a method of dorsal root ganglia stimulation in patients with neuropathic pain: a systematic review. Pain Med. 2020;21:3320-43.

2. Yang F, Yu S, Fan B, et al. The epidemiology of herpes zoster and postherpetic neuralgia in China: results from a cross-sectional study. Pain Ther. 2019:8:249-59.

3. Forbes $\mathrm{HJ}$, Thomas $\mathrm{SL}$, Smeeth $\mathrm{L}$, et al. A systematic review and metaanalysis of risk factors for postherpetic neuralgia. Pain. 2016;157:30-54.

4. Baron R, Binder A, Wasner G. Neuropathic pain: diagnosis, pathophysiological mechanisms, and treatment. Lancet Neurol. 2010;9:807-19.

5. Sampathkumar P, Drage LA, Martin DP. Herpes zoster (shingles) and postherpetic neuralgia. Mayo Clin Proc. 2009;84:274-80.

6. Ojango C, Raguso M, Fiori R, et al. Pulse-dose radiofrequency treatment in pain management-initial experience. Skeletal Radiol. 2018;47:609-18.

7. Castel D, Naveh M, Aharon A, et al. Prolonged analgesic effect of PRF-108 and PRF-110 on post-operative pain in pigs. Pain Ther. 2016;5:29-42.

8. Chang MC. Efficacy of pulsed radiofrequency stimulation in patients with peripheral neuropathic pain: a narrative review. Pain Physician. 2018;21:E225-34.

9. Vanneste T, Van Lantschoot A, Van Boxem K, et al. Pulsed radiofrequency in chronic pain. Curr Opin Anaesthesiol. 2017;30:577-82.

10. Chua NH, Vissers KC, Sluijter ME. Pulsed radiofrequency treatment in interventional pain management: mechanisms and potential indicationsa review. Acta Neurochir (Wien). 2011;153:763-71.

11. World Health Organization. Definition of an older or elderly person. Health Stat Inf Syst. 2014. http://www.who.int/healthinfo/survey/agein gdefnolder/en/.

12. Mizukami A, Sato K, Adachi K, et al. Impact of herpes zoster and postherpetic neuralgia on health-related quality of life in Japanese adults aged 60 years or older: results from a prospective observational cohort study. Clin Drug Investig. 2018;38:29-37.

13. Curran D, Schmidt-Ott R, Schutter U, et al. Impact of herpes zoster and postherpetic neuralgia on the quality of life of Germans aged 50 or above. BMC Infect Dis. 2018;18:496.

14. Watanabe D, Mizukami A, Holl K, et al. The potential public health impact of herpes zoster vaccination of people aged $\geq 50$ years in Japan: results of a Markov model analysis. Dermatol Ther (Heidelb). 2018;8:269-84.

15. Devor M. Chronic pain in the aged: possible relation between neurogenesis, involution and pathophysiology in adult sensory ganglia. J Basic Clin Physiol Pharmacol. 1991;2:1-15. 
16. Watson PN. Postherpetic neuralgia. BMJ Clin Evid. 2010;8:0905.

17. Watson P. Postherpetic neuralgia. Am Fam Physician. 2011;84:690-2.

18. Gruver C, Guthmiller KB. Postherpetic neuralgia. Treasure Island: StatPearls; 2020.

19. Higuchi $Y$, Nashold BS Jr, Sluijter $M$, et al. Exposure of the dorsal root ganglion in rats to pulsed radiofrequency currents activates dorsal horn lamina I and II neurons. Neurosurgery. 2002;50(4):850-5.

20. Hamann W, Abou-Sherif S, Thompson S, et al. Pulsed radiofrequency applied to dorsal root ganglia causes a selective increase in ATF3 in small neurons. Eur J Pain. 2006;10(2):171-6.

21. Hagiwara S, Iwasaka H, Takeshima N, et al. Mechanisms of analgesic action of pulsed radiofrequency on adjuvant-induced pain in the rat: roles of descending adrenergic and serotonergic systems. Eur J Pain. 2009;13:249-52.

22. Ding Y, Li H, Hong T, et al. Efficacy and safety of computed tomographyguided pulsed radiofrequency modulation of thoracic dorsal root ganglion on herpes zoster neuralgia. Neuromodulation. 2019;22:108-14.

23. Ma $K$, Jin $Y$, Huang $X H$, et al. Efficacy of pulsed radiofrequency in the treatment of thoracic postherpetic neuralgia from the angulus costae: a randomized, double-blinded, controlled trial. Pain Physician. 2013:16:15.

24. Pickering $G$. Analgesic use in the older person. Curr Opin Support Palliat Care. 2012;6(2):207-12.

25. Schmader KE, Baron R, Haanpaa ML, et al. Treatment considerations for elderly and frail patients with neuropathic pain. Mayo Clin Proc. 2010;85(3 suppl):S26-32

26. Szczerbinska K, Topor-Madry R. Association between central nervous system drugs and recurrent falling based on prospective falls registration in nursing homes. Eur Geriatr Med. 2013;3:82-6.
27. Kanamori K, Shoji K, Kinoshita N, et al. Complications of herpes zoster in children. Pediatr Int. 2019;61:1216-20.

28. Cahana A, Vutskits L, Muller D. Acute differential modulation of synaptic transmission and cell survival during exposure to pulsed and continuous radiofrequency energy. J Pain. 2003:4:197-202.

29. Tun K, Cemil B, Gurcay AG, et al. Ultrastructural evaluation of pulsed radiofrequency and conventional radiofrequency lesions in rat sciatic nerve. Surg Neurol. 2009;72:496-500.

30. Vatansever D, Tekin I, Tuglu I, et al. A comparison of the neuroablative effects of conventional and pulsed radiofrequency techniques. Clin J Pain. 2008;24:717-24

31. Tekin I, Mirzai H, Ok G, et al. A comparison of conventional and pulsed radiofrequency denervation in the treatment of chronic facet joint pain. Clin J Pain. 2007:23:524-9.

32. Erdine S, Bilir A, Cosman ER, et al. Ultrastructural changes in axons following exposure to pulsed radiofrequency fields. Pain Pract. 2009;9:407-17.

33. Erdine S, Yucel A, Cimen A, et al. Effects of pulsed versus conventional radiofrequency current on rabbit dorsal root ganglion morphology. Eur J Pain. 2005;9:251-6.

34. Kim K, Jo D, Kim E. Pulsed radiofrequency to the dorsal root ganglion in acute herpes zoster and postherpetic neuralgia. Pain Physician. 2017:20:E411-8.

35. Imran JB, Eastman AL. Pneumothorax. JAMA. 2017;318:974

\section{Publisher's Note}

Springer Nature remains neutral with regard to jurisdictional claims in published maps and institutional affiliations.
Ready to submit your research? Choose BMC and benefit from:

- fast, convenient online submission

- thorough peer review by experienced researchers in your field

- rapid publication on acceptance

- support for research data, including large and complex data types

- gold Open Access which fosters wider collaboration and increased citations

- maximum visibility for your research: over $100 \mathrm{M}$ website views per year

At $\mathrm{BMC}$, research is always in progress.

Learn more biomedcentral.com/submissions 